\title{
PRODUÇÃO DE MUDAS DE SCHINUS TEREBINTHIFOLIUS UTILIZANDO BIOSSÓLIDO COMO SUBSTRATO EM DIFERENTES RECIPIENTES E FERTILIZANTES
}

\author{
Production of Schinus terebinthifolius seedlings using biosolide as substrate in different containers and fertilizers
}

\author{
Gerhard Valkinir Cabreira ${ }^{1 *}$; Paulo Sérgio dos Santos Leles; Emanuel José Gomes de Araújo²; Eduardo Vinicius da \\ Silva ${ }^{2}$; Alysson Canabrava Lisboa ${ }^{3}$ [Lucas Nunes Lopes ${ }^{4}$

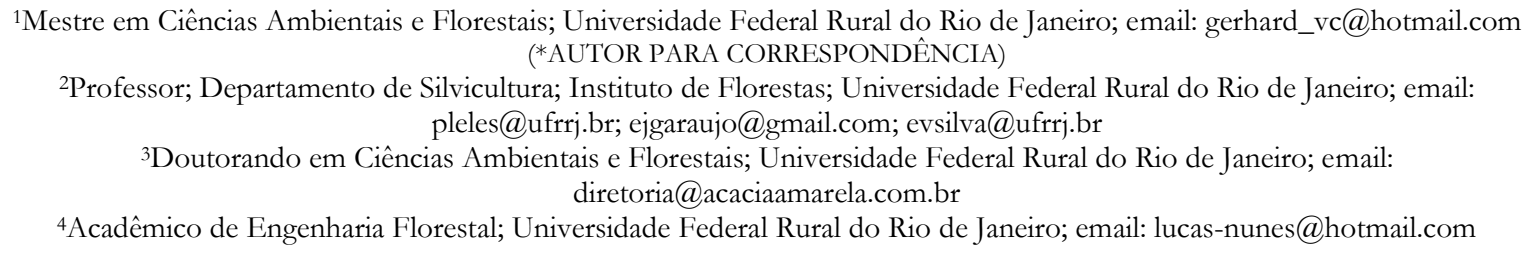

Artigo enviado em 04/02/2017, aceito em 21/05/2017 e publicado em 07/07/2017.

Resumo - O objetivo desse trabalho foi avaliar a influência da capacidade volumétrica de tubetes de polipropileno (110 e de $280 \mathrm{~cm}^{3}$ ), aliado a diferentes doses de Osmocote Plus ${ }^{\circledR}$ N-P-K (15-09-12), na produção de mudas de Schinus terebinthifolius Raddi utilizando biossólido de lodo de esgoto como substrato. Foram utilizados tubetes com volume de 110 e $280 \mathrm{~cm}^{3}$, sendo aplicadas doses de Osmocote Plus ${ }^{\circledR}(15-09-12)$ de 0, 3, 6 e $12 \mathrm{~kg} \mathrm{~m}^{-3}$ de biossólido. O delineamento utilizado foi o inteiramente casualizado (DIC), em esquema fatorial, compondo oito tratamentos com cinco repetições. Avaliou-se o crescimento das mudas em viveiro e sua sobrevivência e o crescimento em campo cinco meses após plantio. Após 112 dias da repicagem, os resultados mostraram que as mudas de aroeira responderam positivamente ao acréscimo de fertilizante de liberação lenta (FLL) junto ao biossólido. O plantio em campo apresentou boa sobrevivência e crescimento das mudas, indicando que apenas os tratamentos sem adubação nos dois recipientes não produziram mudas adequadas ao plantio. Para as condições em que foi realizado o trabalho, indica-se produzir mudas de Schinus terebinthifolius em tubetes de $280 \mathrm{~cm}^{3}$ e dose de $3 \mathrm{~kg}$ de Osmocote Plus ${ }^{\circledR}$ N-P-K (15-09-12) por $\mathrm{m}^{3}$ de biossólido aplicados na época do plantio das sementes.

Palavras-chave - aroeira, lodo de esgoto, osmocote, tubete

Abstract - The objective of this work was to evaluate the influence of the volumetric capacity of polypropylene tubes $(110$ and $280 \mathrm{~cm} 3)$, combined with different doses of Osmocote Plus ${ }^{\circledR}$ NPK (15-09-12), in the production of seedlings of Schinus terebinthifolius using biosolids of sewage sludge as substrate. Rigid plastic tubes with a volume of 110 and $280 \mathrm{~cm}^{3}$ were used, with doses of Osmocote Plus ${ }^{\circledR}(15-09-12)$ of $0,3,6$ and $12 \mathrm{~kg} / \mathrm{m}^{-3}$ of biosolid. The desing used was the completely randomized (DIC), in factorial scheme, composing eight treatments with five replicates. The growth of the seedlings in nursery and their survival and the growth in the field five months after planting were evaluated. After 112 days, the results showed that the aroeira seedlings responded positively to the addition of slow release fertilizer to the biosolids. Field planting showed good survival and seedling growth, indicating that only the treatments without fertilization in the two containers did not produce seedlings suitable for planting. For the conditions that the work was carried out, it indicates to produce seedlings of Schinus terebinthifolius in tubes of $280 \mathrm{~cm}^{3}$ and dose of $3 \mathrm{~kg}$ of Osmocote Plus ${ }^{\circledR}$ N-P-K (15-09-12) per $\mathrm{m}^{3}$ of biosolids applied at the time of planting the seeds.

Keywords - aroeira, sewage sludge, osmocote, rigid plastic tube 


\section{INTRODUÇÃO}

Devido às condições de estresse que as mudas de espécies florestais encontrarão no campo, é importante que as mesmas apresentem determinados padrões de qualidade, pois estes influenciarão na sobrevivência e no crescimento inicial das mudas florestais após o plantio. Segundo Carneiro (1995), vários são os fatores que interferem na qualidade das mudas, dentre eles o tipo de recipiente, seu volume e a composição do substrato.

Entre os tipos de recipientes utilizados para a produção de mudas de espécies florestais nativas usadas na restauração florestal, encontram-se os tubetes de polipropileno. Em comparação aos sacos plásticos, apresentam maior possibilidade de mecanização das operações no viveiro (HAHN et al., 2006; ABREU et al., 2015), além do maior rendimento no transporte e no plantio. No mercado existem vários modelos de tubetes, porém para produção de mudas de espécies nativas, destaca-se os de capacidade volumétrica de 110 e de $280 \mathrm{~cm}^{3}$, por produzir mudas de boa qualidade (LISBOA et al., 2012; STUPP et al., 2015), redução nos custos de transporte e no aumento do rendimento das operações de plantio.

A qualidade do substrato também é importante, pois suas características químicas, físicas e biológicas influenciarão a germinação das sementes e o crescimento das mudas (CARNEIRO, 1995). Um dos substratos com potencial para produção de mudas de espécies florestais é o biossólido de lodo de esgoto (ASSENHEIMER, 2009; ABREU et al., 2017), o qual se destaca por apresentar elevado teor de nutrientes e matéria orgânica (TRIGUEIRO; GUERRINI, 2003). Lima Filho (2015) testando produção de mudas de quatro espécies, usando tubetes com capacidade volumétrica de 55, 110, 180 e $280 \mathrm{~cm}^{3}$ e biossólido como substrato observou que, nos dois modelos de tubete de menor volume, as mudas de Ceiba speciosa apresentaram sintomas visuais de deficiências nutricionais, como amarelecimento das folhas mais novas.

Os biossólidos são relativamente pobres em $\mathrm{K}$, pois durante o tratamento do esgoto, permanece dissolvido na água, sendo perdido neste processo (BERTON; NOGUEIRA, 2010). Além disso, as mudas podem apresentar sintomas de deficiência nutricional devido às perdas por lixiviação, principalmente quando utilizado tubetes de menor volume (MENDONÇA et al., 2008).
A utilização do biossólido na produção de mudas de diferentes espécies florestais nativas em tubetes vem se tornando alternativa para os viveiristas (ABREU et al., 2015; LIMA FILHO, 2015). Porém, devido sua restrição no fornecimento de cátions (ex. $\mathrm{K}^{+}$), a complementação com fertilizantes que apresentem liberação lenta destes nutrientes pode ser uma das alternativas para aumentar a eficiência das adubações e da produção das mudas.

Dentre as espécies utilizadas na restauração florestal encontra-se Schinus terebinthifolius Raddi, conhecida vulgarmente como aroeira pimenteira. Pertencente à família Anacardiaceae, é uma espécie pioneira de característica bastante rústica, podendo ser utilizada em reflorestamentos com condições climáticas adversas, em áreas nos mais diferentes níveis de degradação (CARVALHO, 2003).

Assim, o objetivo deste trabalho foi avaliar a influência da capacidade volumétrica de tubetes de polipropileno (110 e de $280 \mathrm{~cm}^{3}$ ), aliado a diferentes doses de Osmocote Plus ${ }^{\circledR}$ N-P-K (15-09-12), na produção de mudas de Schinus terebinthifolius, utilizando biossólido de lodo de esgoto como substrato.

\section{MATERIAL E MÉTODOS}

\section{Fase de viveiro}

O experimento foi conduzido no viveiro florestal da Universidade Federal Rural do Rio de Janeiro, município de Seropédica, estado do Rio de Janeiro, de junho a dezembro de 2015. As sementes de Schinus terebinthifolius Raddi (aroeira) foram colhidas no município de Seropédica e semeadas em sementeira. Posteriormente, realizou-se a repicagem nos recipientes para evitar perdas no experimento por eventual baixa taxa de germinação.

Os recipientes utilizados foram tubetes com capacidade volumétrica de 110 e de $280 \mathrm{~cm}^{3}$. Os tubetes de $110 \mathrm{~cm}^{3}$ apresentam $13,2 \mathrm{~cm}$ de altura, diâmetro de "boca de $3,7 \mathrm{~cm}$. Para os tubetes de 280 $\mathrm{cm}^{3}$ estes números são $19,0 \mathrm{~cm}$ e $5,2 \mathrm{~cm}$, respectivamente. Ambos apresentam 8 estrias internas.

O substrato utilizado foi composto por $100 \%$ de biossólido enriquecido com as doses de 3, 6 e $12 \mathrm{~g}$ de Osmocote Plus ${ }^{\circledR}$ N-P-K (15-09-12) por $\mathrm{m}^{3}$ de substrato, além de uma testemunha absoluta. Este fertilizante contém também $1 \%$ de $\mathrm{Mg}, 2,3 \%$ de $\mathrm{S}$, $0,05 \%$ de $\mathrm{Cu}, 0,45 \%$ de Fe, $0,06 \%$ de Mn e $0,02 \%$ de Mo em sua composição, sendo considerado de liberação lenta, com tempo de liberação total dos 
nutrientes em torno de 8 a 9 meses. $O$ fertilizante foi aplicado misturado ao biossólido, antes do enchimento dos recipientes.

O biossólido utilizado no experimento foi disponibilizado pela Companhia Estadual de Águas e Esgoto do Rio de Janeiro (CEDAE), sendo proveniente da estação de tratamento de esgoto (ETE) Ilha do Governador, RJ. Para a produção nesta estação, o tratamento do esgoto é feito em nível secundário pelo sistema tecnológico de tratamento de lodos ativados. A estabilização acontece por estabilização biológica em biodigestores, em que o lodo secundário entra em uma centrífuga que o transforma num lodo mais concentrado. $\mathrm{Na}$ ETE Ilha, o lodo é reduzido nos leitos de secagem, esse esgoto tratado provém de áreas urbanas domiciliares e comerciais, não contendo resíduos industriais (ABREU et al., 2017).

Após homogeneização dos substratos, os tubetes foram enchidos de forma manual, sendo coletadas amostras desses substratos, para análise de teores totais de macronutrientes (Tabela 1). O substrato avaliado apresentou densidade de $0,72 \mathrm{~kg}$ $\mathrm{dm}^{-3}$ e matéria orgânica de $35,3 \%$.

Tabela 1 - Análise química de substratos (amostra base seca), em \%, formado por biossólido, com doses crescentes de Osmocote Plus ${ }^{\circledR}$ N-P-K (15-09-12),10 dias após enchimento dos tubetes

\begin{tabular}{ccccccccc}
\hline Dose de Osmocote Plus ${ }^{\circledR}$ & $\begin{array}{c}{ }^{* 1} \mathrm{pH} \\
\left(\mathrm{H}_{2} \mathrm{O}\right)\end{array}$ & ${ }^{*} \mathrm{~N}$ & ${ }^{* 2} \mathrm{P}$ & ${ }^{*} \mathrm{~K}^{+}$ & ${ }^{* 3} \mathrm{Ca}^{2+}$ & ${ }^{* 3} \mathrm{Mg}^{2+}$ & ${ }^{* 3} \mathrm{Al}^{3+}$ \\
\hline 0 & 5,5 & 1,94 & 0,81 & 0,19 & 1,59 & 0,19 & 2,72 \\
3 & 5,0 & 1,97 & 0,88 & 0,21 & 1,91 & 0,19 & 2,91 \\
6 & 5,0 & 2,13 & 0,92 & 0,24 & 1,88 & 0,19 & 2,83 \\
12 & 5,0 & 1,97 & 0,94 & 0,35 & 1,95 & 0,21 & 2,80 \\
\hline
\end{tabular}

${ }^{* 1} \mathrm{pH}$ em água, ${ }^{* 2}$ Extrator Mehlich $1 ;{ }^{*}$ Extrator: $\mathrm{KCl}-1 \mathrm{~mol} \mathrm{~L}^{-1} ;{ }^{* 4} \mathrm{~N}$ total - Digestão Sulfúrica - Destilação Kjeldhal.

O delineamento experimental utilizado foi o inteiramente casualizado, sendo composto por oito tratamentos, com cinco repetições, em esquema fatorial $2 \times 4$ (dois volumes de tubetes e quatro doses de fertilizante de liberação lenta). No tubete de $110 \mathrm{~cm}^{3}$, cada repetição, foi constituída por oito mudas e no tubete $280 \mathrm{~cm}^{3}$ por 6 mudas; como forma de facilitar a logística de distribuição dos tratamentos nas bandejas, que possuíam 96 e 54 células cada, para os tubetes 110 e $280 \mathrm{~cm}^{3}$, respectivamente. Foram usadas parcelas subdivididas no espaço, em que os recipientes constituíram as parcelas e as doses do FLL as subparcelas.

As mudas foram irrigadas através de acompanhamento visual (até duas vezes por dia - início da manhã e final da tarde, por dez minutos a cada irrigação). Ao longo do experimento, foram realizadas limpezas das mudas, sendo retiradas plantas espontâneas presentes no substrato.

Após as mudas apresentarem dois pares de folhas, foram iniciadas as medições de altura da parte aérea, em intervalos de 28 dias, até 112 dias após a repicagem. Nesse período ocorreram quatro medições de altura, sendo que na última medição foi realizada também a medição do diâmetro do coleto.

Após a última medição, para cada espécie foram selecionadas as cinco mudas mais próximas da média de cada tratamento para avaliação de área foliar, com auxílio do medidor LICOR-3600. Dessas mudas, foram separadas a parte aérea e as raízes, sendo estas acondicionadas separadamente em sacos de papel e secos em estufa de circulação de ar forçada a $65^{\circ} \mathrm{C}$ até atingirem peso constante, para obter os pesos de massa de matéria seca da parte aérea (MSPA) e das raízes (MSR).

Após pesagem do material seco em estufa, a MSPA de cada indivíduo foi moída, acondicionadas em sacos plásticos, lacradas e encaminhadas para laboratório para determinação do teor de macronutrientes.

Com os dados de altura das quatro épocas de avaliação foi estimada uma equação de crescimento desta característica, produzidas em cada tubete e dose de FLL aplicada ao substrato. Nos casos em que um mesmo modelo de regressão foi selecionado para diferentes doses de Osmocote Plus ${ }^{\circledR}$, foi aplicado o teste de identidade de Graybill (2000). Este permitiu verificar a possibilidade de uma equação geral representar a relação entre o crescimento em altura das mudas em função do tempo para todas as doses de Osmocote Plus ${ }^{\circledR}$. Este teste baseia-se na comparação entre a soma de quadrado dos resíduos em cada tratamento (modelo completo) e a soma de quadrado da diferença para o modelo ajustado com uma única 
base de dados contendo todos os tratamentos (modelo reduzido). Assim, quando o valor da estatística F calculado for $\geq$ ao seu valor tabelado, indica significância ao nível de 5\% de probabilidade e rejeitase a hipótese $\mathrm{H}_{0}$, ou seja, não é possível utilizar uma única equação para representar todas as doses do FLL.

Os dados de todas as características de crescimento da última avaliação foram submetidos aos testes de pressuposição da análise de variância (normalidade e homogeneidade dos dados), constatando não haver necessidade de transformação. Em seguida, os dados foram submetidos à análise de variância (parcelas subdivididas). Havendo diferença significativa entre os dados dos tubetes, a comparação entre eles foi realizada por meio do teste t, com 5\% de probabilidade. Os dados de doses, em cada recipiente, foram submetidas à análise de regressão. Para todas as análises, foi utilizado o software Sistema de Análise Estatística e Genética (SAEG).

\section{Fase de Campo}

Com o propósito de avaliar a sobrevivência e o crescimento inicial no campo das mudas produzidas na fase de viveiro, foram selecionadas 20 mudas (altura e diâmetro de coleto mais próximos dos valores médios da última medição) de cada tratamento para o plantio. Esse plantio foi realizado em área de reflorestamento localizada em área da Estação Ecológica Estadual de Guaxindiba, em São Francisco do Itabapoana, RJ.

A área apresenta altitude média de 25 metros e relevo plano. Análises de campo realizadas pela equipe, indicaram um solo com textura argilo-arenosa, com $60 \%$ de areia, 38\% de argila e 2\% de silte, classificando-o como ARGISSOLO VERMELHOAMARELO. O clima da região segundo a classificação de Köppen é CWa, com predominância de chuvas nos meses de dezembro a março.

O plantio foi realizado em dezembro de 2015, em sulcos de $50 \mathrm{~cm}$ de profundidade, espaçamento $3 \mathrm{x}$ $2 \mathrm{~m}$ e abertura das covas manualmente. Em seguida, as mudas foram distribuídas em 20 linhas de plantio, intercalando uma muda de aroeira e três mudas de outras espécies. Após o plantio, fez-se a mensuração da altura das plantas de aroeira, além do croqui de localização de todas as plantas, com a identificação dos tratamentos. O delineamento experimental utilizado foi o inteiramente casualizado, sendo cada muda de aroeira plantada uma repetição. Assim, o experimento apresentou 160 mudas de aroeira (oito tratamentos com 20 mudas cada).

Segundo dados coletados em pluviômetro instalado na localidade da área experimental, entre 01 dezembro de 2015 a 30 de novembro de 2016 a precipitação acumulada foi de $891 \mathrm{~mm}$. Nos cinco primeiros meses após o plantio; dezembro, janeiro, fevereiro, março e abril houve precipitação de 137,5; 285,7; 131,7; 101,5 e 49,9 mm; respectivamente com $10,18,6,8$ e 5 dias chuvosos em cada mês. Nos demais meses, a precipitação foi reduzida.

As avaliações consistiram da mensuração da altura aos cinco meses após o plantio e altura e diâmetro ao nível do solo (DNS) aos 12 meses. Nestas ocasiões verificou-se a planta estava viva ou morta, obtendo-se a taxa de sobrevivência das mudas advindas dos diferentes tratamentos.

Avaliou-se a normalidade e a homogeneidade de variâncias do resíduo de altura e do DNS mensurados. Os resultados foram submetidos à análise de variância. Para todas as análises, foi utilizado o software Sistema de Análise Estatística e Genética (SAEG).

\section{RESULTADOS E DISCUSSÃO}

\section{Fase de viveiro}

Nas Figuras 1A e 1B são apresentadas o crescimento em altura das mudas de aroeira, produzidas nos tubetes de 110 e $280 \mathrm{~cm}^{3}$, respectivamente, ao longo do tempo (28 a 112 dias após repicagem). As linhas de regressão representam as três doses do fertilizante de liberação lenta N-P-K (1509-12) e uma testemunha absoluta. Conforme esperado, verifica-se crescimento linear da altura das mudas em função do tempo de repicagem. Além disso, percebe-se que o uso do fertilizante acelerou o crescimento das mudas, nos tratamentos em que foram enriquecidos com o fertilizante.

O teste de identidade de modelos constatou que, em ambos os volumes de tubete, houve diferença significativa entre as equações ajustadas para cada dose de fertilizante de liberação lenta aplicada. Nos tubetes de $110 \mathrm{~cm}^{3}$, verificou-se que as mudas de aroeira produzidas nos tratamentos com doses de 6 e $12 \mathrm{~kg} \mathrm{~m}^{-3}$ apresentaram equações idênticas estatisticamente, apresentando médias de altura superior as das mudas das doses 0 e $3 \mathrm{~kg} \mathrm{~m}^{-3}$, gerando as equações que são mostradas na Figura 1A.

Para as mudas produzidas nos tubetes de 280 $\mathrm{cm}^{3}$, as equações dos três tratamentos que receberam a fertilização foram idênticas estatisticamente e superiores ao tratamento que não recebeu o fertilizante de liberação lenta, gerando as equações que são mostradas na Figura 1B. Assim, pela característica 
altura e usando biossólido como substrato, para produção de mudas de aroeira, em tubete de $110 \mathrm{~cm}^{3}$ deve-se utilizar $6 \mathrm{~kg}$ de Osmocote Plus ${ }^{\circledR}$ N-P-K (1509-12) por $\mathrm{m}^{3}$ de biossólido e para tubete de $280 \mathrm{~cm}^{3} \mathrm{a}$ dose será de $3 \mathrm{~kg} \mathrm{~m}^{-3}$. Esta diferença de doses entre recipientes é devido ao próprio volume destes e a quantidade de substrato ofertada em cada um, além da quantidade de nutrientes e matéria orgânica.

O maior crescimento das mudas que receberam maiores doses de fertilizante pode ser explicado também pela maior sensibilidade da altura em relação à adubação nitrogenada, pois segundo Hahn et al. (2006), substratos ricos em nitrogênio, tendem a produzir mudas florestais com maior altura. O biossólido, normalmente é relativamente rico em $\mathrm{N}$, conforme mencionado em trabalhos como de Assenheimer (2009), Maas (2010) e Abreu et al., (2017) e observado pela Tabela 1. Esta resposta à adubação no crescimento em altura das mudas, também ocorreu devido à aroeira ser uma espécie pioneira, de crescimento relativamente rápido e responsiva à fertilização (CARVALHO, 2003).

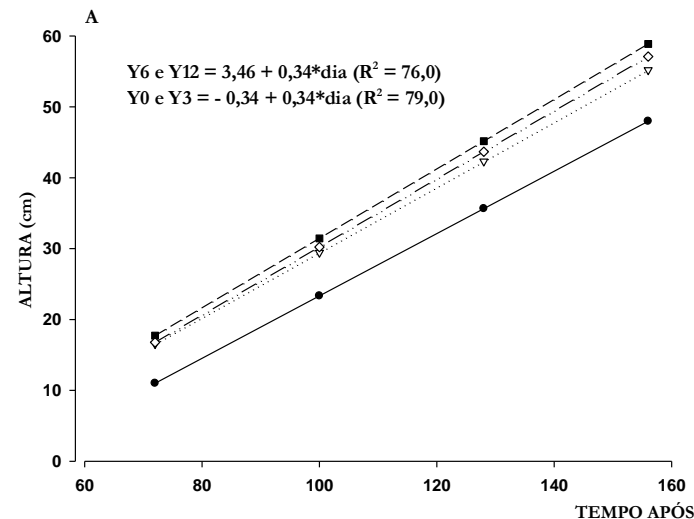

Figura 1 - Altura de mudas de Schinus terebenthifolius após repicagem, produzidas em tubetes $110 \mathrm{~cm}^{3}$ e $280 \mathrm{~cm}^{3}$, sob quatro doses de Osmocote Plus ${ }^{\circledR}$ N-P-K (15-09-12), utilizando biossólido como substrato. *significativo ao nível de $1 \%$ de probabilidade pelo teste $t$.

Assim, espera-se que, quanto melhores as condições de nutrição, maior será seu crescimento vegetativo. Contudo, Rossa et al. (2013) salientam que acréscimos cada vez maiores de adubação (principalmente o nitrogênio) poderão acarretar num elevado incremento em altura, podendo ocasionar o estiolamento das mudas de aroeira.

Observa-se ainda pela Figura 1 que as mudas de aroeira, em todos os tratamentos, aos 112 dias (última medição), ainda estavam com crescimento linear em altura, indicando que teoricamente, poderiam continuar no viveiro. No entanto, segundo informações de José et al. (2005), mudas desta espécie com $25 \mathrm{~cm}$ de altura já possuem tamanho adequado para serem plantadas no campo, desde que devidamente rustificadas. Assim, as mudas de aroeira com 56 dias após repicagem produzidas nos tubetes de
$280 \mathrm{~cm}^{3}$ com substrato enriquecido com Osmocote Plus ${ }^{\circledR}$ estavam com altura adequada para serem levadas para o campo e usando tubete de $110 \mathrm{~cm}^{3}$, esta idade seria aos 84 dias, maximizando o uso do viveiro.

$\mathrm{Na}$ Tabela 2 é apresentado resumo da análise de variância dos parâmetros morfológicos da última medição, avaliados na época de expedição das mudas para o campo (112 dias após a repicagem). Constata-se que, para todas as características avaliadas, ocorreram diferenças significativas entre as médias das mudas produzidas nos dois volumes de tubetes. Também ocorreram diferenças significativas entre doses de fertilizante em todas as variáveis. A interação entre recipiente e doses de fertilizante de liberação lenta não foi significativa apenas para massa de matéria seca de raízes. 
Tabela 2 - Resumo da análise de variância (quadrado médio) para altura da parte aérea, diâmetro do coleto, área foliar, massa de matéria seca de parte aérea (MSPA) e massa de matéria seca de rázes (MSR) em função de diferentes recipientes e doses de Osmocote Plus ${ }^{\circledR}$ N-P-K (15-09-12) para produção de mudas de Schinus terebenthifolius, aos 112 dias após a repicagem

\begin{tabular}{lllllll}
\hline Fonte de Variação & GL & Altura & Diâmetro & Área foliar & MSPA & MSR \\
\hline Recipiente & 1 & $1992,5^{*}$ & $19,71^{*}$ & $419508^{*}$ & $68,77^{*}$ & $6,42^{*}$ \\
Erro A & 8 & 16,2 & 0,04 & 1339 & 1,28 & 0,23 \\
Dose & 3 & $81,4^{*}$ & $6,18^{*}$ & $74306^{*}$ & $16,13^{*}$ & $2,25^{*}$ \\
Recipiente*Dose & 3 & $21,5^{*}$ & $0,41^{*}$ & $15040^{*}$ & $4,63^{*}$ & $0,61^{\mathrm{ns}}$ \\
Erro B & 24 & 4,1 & 0,14 & 4362 & 1,77 & 0,44 \\
\hline $\begin{array}{l}\text { GL }=\text { grau de liberdade. * } \\
\text { teste F. }\end{array}$ & &
\end{tabular}
teste F.

Constatou-se que, aos 112 dias após repicagem, as mudas produzidas nos tubetes de 280 $\mathrm{cm}^{3}$ apresentaram médias de todas as características morfológicas significativamente superiores. Isto ocorreu provavelmente devido ao maior volume de biossólido oferecido pelo tubete de $280 \mathrm{~cm}^{3}$, o qual possui mais espaço para o crescimento radicular, disponibilidade de água, nutrientes e matéria orgânica, conforme também observado por Lisboa et al. (2012) trabalhando com duas espécies florestais, Abreu et al. (2015) para mudas de Enterolobium contortisiliquum e por Lima Filho (2015) com quatro espécies arbóreas de Mata Atlântica. José et al. (2005) também relatam que o volume do tubete tem efeito significativo sobre as variáveis morfológicas das mudas e desta forma, podese tornar um fator limitante ao crescimento das mudas.

Cunha et al. (2005), avaliando quatro tamanhos de recipientes para produção de mudas de ipê-roxo (Tabebuia impetiginosa), constataram que os recipientes de maiores dimensões proporcionaram tendência de maior crescimento das mudas, implicando na diminuição do ciclo de produção destas. Os autores explicam que isto ocorreu devido ao maior volume de substrato ofertado. Porém, este trabalho de Cunha et al. (2005) não menciona se os maiores recipientes proporcionaram maior sobrevivência das mudas no campo e também, sobre o rendimento de transporte das mudas viveiro - campo, que são parâmetros importantes quando estuda recipientes.
Verifica-se também pela Tabela 2 que houve respostas significativas de crescimento em função da dose de Osmocote Plus ${ }^{\circledR}$ aplicada, envolvendo os dois volumes de tubetes. Ao testar os modelos, constatou-se que o modelo linear foi o de melhor ajuste em relação às características de crescimento, porém estas apresentaram coeficiente de determinação $\left(\mathrm{R}^{2}\right)$ relativamente baixo (inferior a $35 \%$ ), devido à grande dispersão dos dados, por trabalhar com os valores das mudas produzidas nos dois volumes de tubetes.

Ao realizar o desdobramento, constata-se que as mudas de aroeira produzidas nos tubetes de 110 $\mathrm{cm}^{3}$, aos 112 dias após a repicagem, apresentaram crescimento linear com as doses de Osmocote Plus ${ }^{\circledR}$ aplicadas no biossólido, na época de enchimento dos recipientes (Figura 2). Já as mudas produzidas nos tubetes de $280 \mathrm{~cm}^{3}$, apresentaram equação quadrática para altura, área foliar e massa de matéria seca de parte aérea; e equação raiz quadrática para diâmetro ao nível do coleto, ou seja, isso indica uma dose máxima para o crescimento das mudas de aroeira. Esta diferença de comportamento de crescimento das mudas nos dois volumes de tubetes é devido ao pequeno volume de biossólido no tubete de $110 \mathrm{~cm}^{3}$, e com isso, segundo Lisboa et al. (2012), não atendendo a demanda de nutrientes da planta, além da maior restrição do crescimento radicular das mudas neste volume de tubete. 

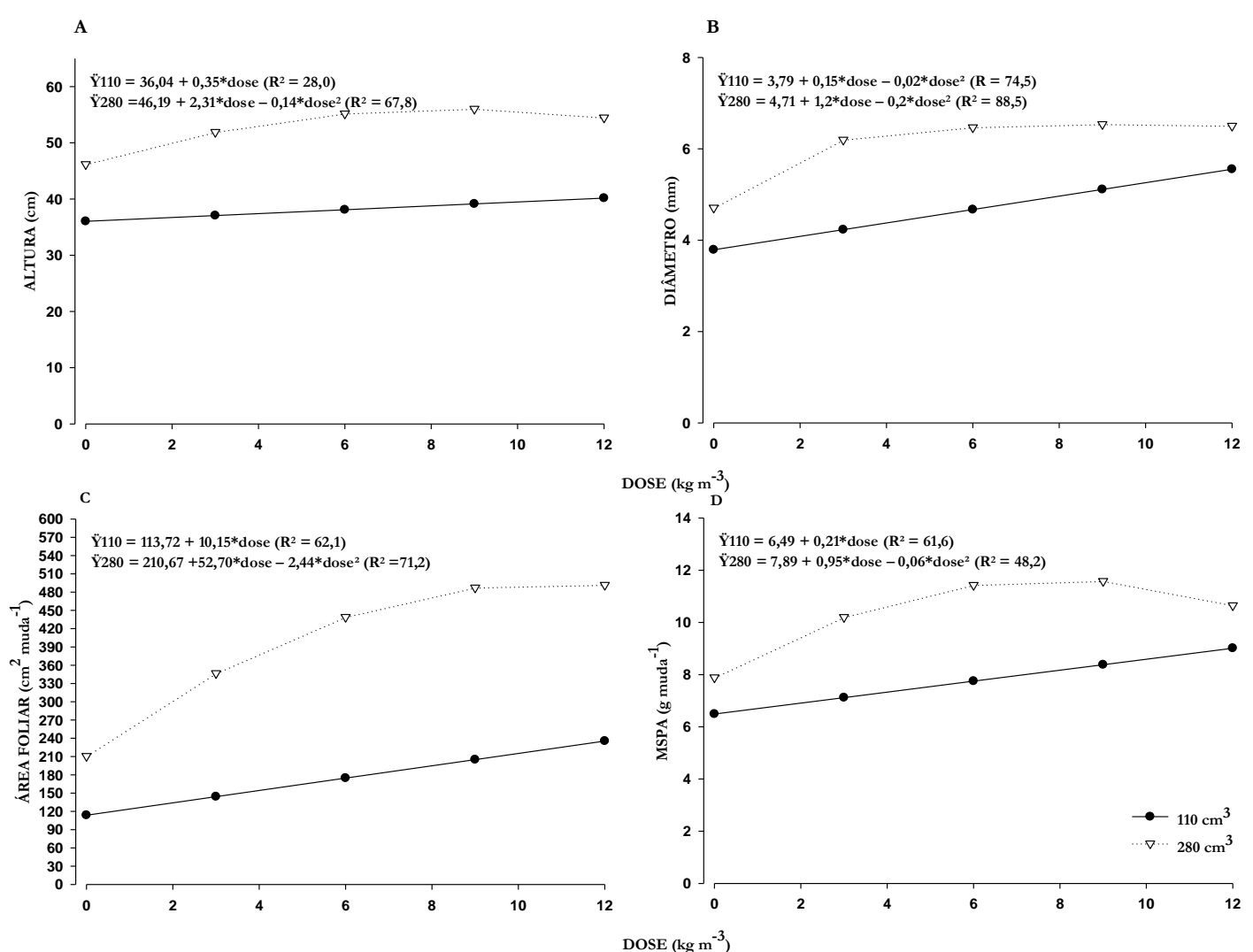

Figura 2 - Crescimento de mudas de Schinus terebenthifolius em função de diferentes doses de Osmocote Plus ${ }^{\circledR}$ N-PK (15-09-12) produzidas em dois volumes de tubetes, utilizando biossólido como substrato. MSPA = massa de matéria seca de parte aérea. * significativo ao nível de $1 \%$ de probabilidade pelo teste t; ${ }^{* *}$ significativo ao nível de $5 \%$ de probabilidade pelo teste $t$.

José et al. (2009), avaliando doses de fertilização de liberação lenta na qualidade de mudas de aroeira produzidas em tubetes de 50 e $150 \mathrm{~cm}^{3}$, observaram que os dois volumes de tubetes tiveram modelos com ajuste linear para a maioria das variáveis, exceto a altura, o que corrobora com este trabalho, em que nos tubetes de $110 \mathrm{~cm}^{3}$ observou-se um comportamento linear com o aumento das doses de Osmocote Plus ${ }^{\circledR}$.

Como verificado para as mudas de aroeira produzidas nos tubetes de $280 \mathrm{~cm}^{3}$, observa-se em outros trabalhos um comportamento quadrático de crescimento de mudas florestais com o aumento das doses de fertilizantes (BRONDANI et al., 2008; ROSSA et al., 2013; STÜPP et al., 2015). Segundo Rossa et al. (2013), esse tipo de comportamento demonstra que as plantas apresentam um máximo crescimento biológico e que não crescem na mesma proporção em que se aplicam os fertilizantes, indicando a chamada Dose de Máxima Eficiência Técnica (DMET).
Ao calcular a DMET do crescimento em altura, diâmetro de coleto, área foliar e MSPA, das mudas de aroeira produzidas em tubetes de $280 \mathrm{~cm}^{3}$, encontrou-se valores de 8,5;9,0;10,8 e 7,9 g de Osmocote Plus ${ }^{\circledR} \quad \mathrm{N}-\mathrm{P}-\mathrm{K} \quad(15-09-12)$ por $\mathrm{m}^{3}$ de biossólido aplicados na época da semeadura. $\mathrm{O}$ valor médio de Osmocote Plus ${ }^{\circledR}$ que proporcionou o maior crescimento foi de $9,0 \mathrm{~g} \mathrm{~m}^{-3}$ de substrato, isso indica que; se for levado em consideração apenas essas características de crescimento no viveiro, sem levar em consideração a sobrevivência e o crescimento inicial no campo; esta dose seria a mais recomendada para produzir mudas de aroeira, quando utilizado tubetes de $280 \mathrm{~cm}^{3}$ e substrato com $100 \%$ de biossólido.

Esses valores de DMET confirmam que aplicações de doses exageradas não irão oferecer um crescimento proporcional à quantidade empregada, além de aumentar os riscos de contaminação ambiental (BETTIOL; CAMARGO, 2006; COSCIONE et al., 
2010) e elevar os custos de produção das mudas florestais no viveiro.

Caldeira et al. (2008) estabeleceram limite mínimo de $30 \mathrm{~cm}$ de altura e 2,2 $\mathrm{mm}$ de diâmetro do coleto para que mudas de aroeira sejam encaminhadas para o campo. José et al. (2005) destacam que para a espécie aroeira, a altura e o diâmetro do coleto adequado para expedição das mudas para o campo encontra-se respectivamente na faixa dos $25 \mathrm{~cm}$ e 3,0 $\mathrm{mm}$, com 90 dias após a repicagem. Sendo assim, as mudas de todos os tratamentos (produzidas em tubetes de 110 e $280 \mathrm{~cm}^{3}$ com doses de 0, 3, 6 e $12 \mathrm{~kg} \cdot \mathrm{m}^{-3}$ de substrato), encontravam-se nos padrões estabelecidos por estes autores para serem plantadas, levando-se em consideração a altura e o diâmetro do coleto, sendo importante fazer testes no campo.

Com base na interação significativa entre recipiente e dose da análise de variância (Tabela 2), para cada dose foi realizado teste $t$ para verificar a ocorrência de diferença significativa das características de crescimento entre os recipientes. Constata-se pela Tabela 3, que para todas as doses, em todas as características de crescimento, com exceção do peso da massa de matéria seca de raízes, as mudas produzidas em tubetes de $280 \mathrm{~cm}^{3}$ foram significativamente superiores do que as mudas produzidas nos tubetes de $110 \mathrm{~cm}^{3}$.

Tabela 3: Valores médios das características de crescimento de mudas de Schinus terebenthifolius, aos 112 dias após a repicagem, em doses de Fertilizante de liberação lenta N-P-K (15-09-12), utilizando tubetes de capacidade volumétrica de 110 e $280 \mathrm{~cm}^{3}$

\begin{tabular}{cccccccccccc}
\hline \multirow{2}{*}{ Dose de FLL } & \multicolumn{2}{c}{ Altura $(\mathrm{cm})$} & \multicolumn{2}{c}{ DC $(\mathrm{mm})$} & \multicolumn{2}{c}{ AF $\left(\mathrm{cm}^{2}\right)$} & \multicolumn{2}{c}{ MSPA (g) } & \multicolumn{2}{c}{ MSR (g) } \\
\hline kg.m $\mathrm{m}^{-3}$ & 110 & 280 & 110 & 280 & 110 & 280 & 110 & 280 & 110 & 280 \\
0 & 36,2 & $46,0^{*}$ & 3,6 & $4,7^{*}$ & 117 & $208^{*}$ & 6,6 & $7,8^{*}$ & 5,5 & $5,8^{\mathrm{ns}}$ \\
3 & 36,4 & $52,5^{*}$ & 4,3 & $6,2^{*}$ & 136 & $353^{*}$ & 6,9 & $10,6^{*}$ & 5,9 & $7,3^{\mathrm{ns}}$ \\
6 & 39,0 & $54,8^{*}$ & 4,9 & $6,5^{*}$ & 181 & $434^{*}$ & 7,8 & $11,3^{*}$ & 6,1 & $7,1^{\mathrm{ns}}$ \\
12 & 39,9 & $54,6^{*}$ & 5,4 & $6,5^{*}$ & 234 & $492^{*}$ & 9,0 & $11,2^{*}$ & 6,4 & $6,9^{\mathrm{ns}}$ \\
\hline
\end{tabular}

DC - Diâmetro do coleto; AF - Área foliar; MSPA - Matéria seca da parte aérea; MSR - Matéria seca de raiz. * significativo ao nível de $90 \%$ de probabilidade pelo teste $t$. ns não significativo ao nível de $90 \%$ de probabilidade pelo teste $\mathrm{t}$.

A diferença significativa entre os recipientes pode ser justificada pelo menor volume de substratos, e com isso menor quantidade de água e de nutrientes disponíveis às mudas de aroeira. José et al. (2005) destacam que, o volume do tubete tem efeito significativo sobre as características morfológicas das mudas e desta forma, pode-se tornar um fator limitante ao crescimento da muda, o que provavelmente ocorreu neste trabalho. Ferraz e Engel (2011), estudando três espécies nativas de diferentes estágios ecológicos (Hymenea coubaril, Tabebuia chrysotricha e Parapiptadenia rigida), verificaram que as plantas produzidas com substrato comercial orgânico no tubete de $300 \mathrm{~cm}^{3}$ (maior recipiente avaliado) foram as que obtiveram maior crescimento, possibilitando reduzir o tempo de produção em até 70 dias. Viana et al. (2008), em estudo com Baubinia forficata e Teixeira et al. (2005), avaliando Jacaranda micrantha e Triplaris americana, também verificaram efeitos de diferentes tamanhos de recipientes na produção de mudas florestais.

Carneiro (1995) argumenta que, o volume do tubete irá influenciar também na disponibilidade de nutrientes e água, além disso, tubetes de maior volume irão promover um maior crescimento e melhor arquitetura de raízes. Contudo, quanto maior o recipiente maior será o consumo com substrato, além de aumentar a área do viveiro para produzir as mudas além de aumentar os custos de transporte das mudas do viveiro para a área de plantio.

Essas diferenças em altura e diâmetro do coleto, por exemplo, podem ser reduzidas conforme ocorre compensação nutricional das mudas produzidas em tubetes menores, pela maior aplicação de fertilizantes, com maior frequência de aplicações, pois quanto menor o recipiente, menor será a permanência dos elementos no substrato, tanto pelo consumo da muda, quanto pela lixiviação ocasionada pela irrigação (JOSÉ et al., 2005).

Avaliando os resultados do teor médio de macronutrientes da parte aérea das mudas de aroeira entre os recipientes e as diferentes doses de Osmocote Plus ${ }^{\circledR}$ (Tabela 4), observa-se em geral, que a concentração dos macronutrientes avaliados seguiu à ordem $\mathrm{Ca}>\mathrm{N}>\mathrm{K}>\mathrm{P}>\mathrm{Mg}$. Esse padrão foi seguido 
para as mudas nos dois recipientes, mesmo quando acrescentado doses de fertilizante de liberação lenta no substrato. Essa maior presença do Ca nas mudas pode estar relacionado ao fato desse nutriente apresentar função estrutural, em que boa parte dele estará presente na parede celular (TAIZ; ZEIGER, 2013).

Tabela 4 - Teor médio de macronutrientes da parte aérea, em $\mathrm{g} \mathrm{kg}^{-1}$, em mudas de Schinus terebenthifolius submetidas a diferentes doses de Osmocote Plus ${ }^{\circledR}$ em dois volumes de tubete, aos 112 dias após a repicagem.

\begin{tabular}{ccccccc}
\hline Recipiente & Dose $\left(\mathrm{kg} \mathrm{m}^{-3}\right)$ & $\mathrm{N}$ & $\mathrm{P}$ & $\mathrm{K}$ & $\mathrm{Ca}$ & $\mathrm{Mg}$ \\
\hline \multirow{3}{*}{$110 \mathrm{~cm}^{3}$} & 0 & 16,38 & 3,92 & 6,74 & 29,57 & 0,80 \\
& 3 & 13,75 & 4,30 & 10,42 & 22,96 & 1,11 \\
& 6 & 13,79 & 2,77 & 11,78 & 25,91 & 0,97 \\
$280 \mathrm{~cm}^{3}$ & 12 & 14,71 & 1,85 & 10,39 & 21,15 & 0,96 \\
& 0 & 20,37 & 2,49 & 9,82 & 21,92 & 0,67 \\
& 3 & 17,09 & 2,09 & 10,33 & 27,21 & 0,76 \\
& 6 & 18,61 & 2,11 & 12,74 & 26,41 & 1,10 \\
\hline
\end{tabular}

Percebe-se também que em geral, ocorreu um menor teor dos macronutrientes conforme o aumento das doses, porém com pouca variação. Esse padrão se repetiu em ambos os recipientes. Isso pode estar associado ao efeito da diluição, no qual o aumento na produtividade faz com que ocorra uma diminuição da concentração de alguns elementos na planta (ROSSA et al., 2015). As mudas com maior crescimento demonstraram maior eficiência na utilização desses nutrientes em produção de biomassa, fator esse que pode ser comprovado através da análise dos conteúdos totais desses elementos presente na matéria seca da parte aérea das mudas. Essa maior disponibilização de nutrientes acabou não favorecendo a absorção e utilização dos macronutrientes pelas mudas de aroeira, e isso segundo Sorreano et al. (2012), pode causar efeitos fitotóxicos na planta.

Ao analisar respostas de conteúdo de macronutrientes das mudas para cada tipo de tubete (Tabela 5), constatam-se comportamentos diferenciados. Para as mudas dos tubetes de $110 \mathrm{~cm}^{3}$ não houve respostas para $\mathrm{P}, \mathrm{Ca}$ e Mg. Já nos tubetes de $280 \mathrm{~cm}^{3}$, verificou-se respostas para todos os macronutrientes, sendo que para $\mathrm{N}, \mathrm{P}$ e $\mathrm{Mg}$ as respostas foram lineares. Para $\mathrm{K}$ e Ca obteve-se DMET de 11,4 e 5,4 g.m $\mathrm{m}^{-3}$ de biossólido, respectivamente.

Tabela 5 - Equações do conteúdo total médio dos macronutrientes presentes na biomassa de matéria seca da parte aérea, em $\mathrm{g}$ muda $^{-1}$, em função de diferentes doses de Osmocote Plus ${ }^{\circledR}$, de mudas de Schinus terebenthifolius produzidas em dois volumes de tubete, aos 112 dias após a repicagem

\begin{tabular}{|c|c|c|}
\hline Elemento & $110 \mathrm{~cm}^{3}$ & $280 \mathrm{~cm}^{3}$ \\
\hline $\mathrm{N}$ & $\hat{\mathrm{Y}}=0,108-0,022^{*} \cdot \sqrt{\text { dose }}+0,008^{*} \cdot$ dose & $\hat{Y}=0,158+0,007^{*} \cdot$ dose \\
\hline$N$ & DMET $=1,9$ & $\mathrm{R}^{2}=63,7$ \\
\hline $\mathrm{P}$ & $\hat{Y}=\bar{Y}$ & $\begin{array}{l}\mathrm{Y}=0,020+0,0004^{*} \cdot \text { dose } \\
\mathrm{R}^{2}=34,8\end{array}$ \\
\hline K & $\begin{array}{l}\mathrm{Y}=0,044+0,011^{*} \cdot \text { dose }-0,0006^{*} \cdot \text { dose }^{2} \mathrm{R}^{2}=80,0 \\
\mathrm{DMET}=9,2\end{array}$ & $\begin{array}{l}\hat{\mathrm{Y}}=0,074+0,014^{*} \cdot \operatorname{dose}-0,0006^{* *} \cdot \operatorname{dos}^{2} \mathrm{R}^{2}=74,4 \\
\mathrm{DMET}=11,4\end{array}$ \\
\hline $\mathrm{Ca}$ & $\hat{Y}=\bar{Y}$ & $\begin{array}{l}\hat{\mathrm{Y}}=0,169+0,111^{*} \cdot \sqrt{\text { dose }}-0,024^{*} \cdot \text { dose } \\
\mathrm{R}^{2}=59,6 \quad \text { DMET }=5,4\end{array}$ \\
\hline $\mathrm{Mg}$ & $\hat{Y}=\bar{Y}$ & $\begin{array}{l}\mathrm{Y}=0,006+0,0007^{*} \cdot \text { dose } \\
\mathrm{R}^{2}=71,9\end{array}$ \\
\hline
\end{tabular}

*significativo ao nível de $1 \%$ de probabilidade pelo teste $\mathrm{t} ;{ }^{*}$ significativo ao nível de $5 \%$ de probabilidade pelo teste $\mathrm{t}$. 
De maneira geral, pelas equações, o conteúdo total de N, P, K, Ca e Mg foi superior com a utilização do FLL em relação às plantas produzidas em tubetes sem fertilização. Em relação à testemunha, o efeito mais marcante foi para o K. Isso possivelmente pode estar associado ao fornecimento mais rápido desse nutriente. Uma possível carência de K pode causar uma redução na produção de massa seca das mudas, pois ele ativa enzimas que estão envolvidas na respiração e na fotossíntese, além disso, o $\mathrm{K}$ irá regular o potencial osmótico da célula vegetal e a abertura e fechamento dos estômatos (TAIZ; ZEIGER, 2013).

Apesar de Schinus terebenthifolius ser classificada como pioneira, com rápido crescimento e maior exigência nutricional na fase inicial de crescimento (GONÇALVES et al., 2001; CARVALHO, 2003; PAIVA et al., 2009), observa-se que a maior disponibilização de nutrientes não irá favorecer a absorção de macronutrientes pelas plantas, podendo até causar efeitos fitotóxicos (TAIZ; ZEIGER, 2013; SORREANO et al., 2012), como no caso de $\mathrm{K}$ em ambos os tubetes, $\mathrm{N}$ em tubetes de $110 \mathrm{~cm}^{3}$ e Ca em tubetes de $280 \mathrm{~cm}^{3}$. O aumento demasiado de nutrientes também pode elevar as perdas por lixiviação (FERNANDES, 2006) e por adsorção no solo (NOVAIS et al., 2007), além dos riscos de contaminação ambiental (BETTTIOL; CAMARGO, 2006; COSCIONE et al., 2010).

\section{Fase de Campo}

Aos cinco meses após o plantio, as plantas de Schinus terebenthifolius apresentaram taxa de sobrevivência variando de 90 a 100\% (Tabela 6), valor considerado ótimo (BELLOTTO et al., 2009). Isto ocorreu devido à boa precipitação que ocorreu nos quatro meses após plantio (dezembro a março) e boa capacidade de retenção de água do solo argilosso de textura argilo-arenosa. Na avaliação realizada aos doze meses após o plantio, as plantas de aroeira apresentaram taxa de sobrevivência em campo variando entre $75 \%$ a $95 \%$ para os diferentes tratamentos. Esta queda da taxa de sobrevivência foi devido aos meses de junho a outubro não ter ocorrido forte precipitação na região. Para o estado do Rio de Janeiro, segundo Art. $8^{\circ}$, item 4.2, da Resolução INEA $\mathrm{n}^{\circ}$ 89, de 03/06/14 (INEA, 2014), é aceitável índice de mortalidade por espécie de até $20 \%$. Nesse contexto, apenas as mudas produzidas sem fertilização, em ambos os recipientes, não se enquadraram nas recomendações indicadas.

De maneira geral, as mudas de aroeira originárias de tubete $110 \mathrm{~cm}^{3}$ apresentaram taxa de sobrevivência bastante similar ao das mudas produzidas no tubete $280 \mathrm{~cm}^{3}$, demonstrando a rusticidade dessa espécie, destacando que ela pode ser levada para campo mesmo quando produzidas em recipientes de menor volume.

Nas condições em que as plantas foram expostas, as mudas de aroeira produzidas em tubete de $280 \mathrm{~cm}^{3}$, que receberam uma dose de $3 \mathrm{~kg}$ de osmocote por $\mathrm{m}^{3}$ de biossólido, de maneira geral, foram as que apresentaram melhor desempenho em altura, ao longo de um ano. Pela tabela 6, observa-se ainda, que as plantas de aroeira produzidas em tubete de $280 \mathrm{~cm}^{3}$ apresentaram valores significativamente superior do que as de tubetes de $110 \mathrm{~cm}^{3}$ apenas para altura, aos $5 \mathrm{e}$ 12 meses, porém destaca-se a redução dessa diferença ao longo desse tempo, com um ganho maior em incremento das plantas de aroeira produzidas em tubete de $110 \mathrm{~cm}^{3}$. Segundo Carneiro (1995), as diferenças de crescimento de mudas produzidas de diferentes recipientes tendem a desaparecer ao longo do tempo no campo, conforme observado, também por José et al. (2005) com Schinus terebinthifolius usando tubetes de 50 e $150 \mathrm{~cm}^{3}$ e por Abreu et al. (2015) aos cinco meses após o plantio em mudas de Enterolobium contortisiliquum, produzidas em diferentes recipientes. 
Tabela 6 - Sobrevivência e crescimento de Schinus terebenthifolius, oriundas de dois volumes de tubete e submetidas a diferentes doses de Osmocote Plus ${ }^{\circledR}$, aos cinco e doze meses após o plantio, em área de reflorestamento, município de São Francisco do Itabapoana - RJ

\begin{tabular}{|c|c|c|c|c|c|c|c|}
\hline \multirow{2}{*}{$\begin{array}{c}\text { Volume do } \\
\text { tubete }\end{array}$} & \multirow[b]{2}{*}{ Dose } & Plantio & \multicolumn{2}{|c|}{------- 5 meses ------- } & \multicolumn{3}{|c|}{-------------- 12 meses -------------- } \\
\hline & & Alt. (cm) & Sobrev. $(\%)$ & Alt. (cm) & Sobrev. $(\%)$ & Alt. (cm) & $\mathrm{DNS}(\mathrm{mm})$ \\
\hline \multirow{4}{*}{$110 \mathrm{~cm}^{3}$} & 0 & 45,4 & 95 & 53,3 & 75 & 68,7 & 21,0 \\
\hline & 3 & 43,6 & 100 & 56,6 & 90 & 64,1 & 19,2 \\
\hline & 6 & 46,8 & 100 & 58,5 & 90 & 72,1 & 20,3 \\
\hline & 12 & 49,2 & 100 & 60,3 & 90 & 72,5 & 19,5 \\
\hline & Média & 46,3 & 97,5 & 57,2 & 86,2 & 69,3 & 20,0 \\
\hline \multirow{5}{*}{$280 \mathrm{~cm}^{3}$} & 0 & 54,7 & 90 & 65,4 & 75 & 71,7 & 19,3 \\
\hline & 3 & 64,3 & 90 & 77,3 & 85 & 87,0 & 23,5 \\
\hline & 6 & 64,5 & 95 & 72,3 & 85 & 84,6 & 22,2 \\
\hline & 12 & $\begin{array}{r}65,4 \\
-\end{array}$ & 100 & 74,7 & 95 & 80,7 & 23,9 \\
\hline & Média & 62,2 & 93,7 & 72,4 & 85,0 & 81,0 & 22,2 \\
\hline
\end{tabular}

Médias das mudas produzidas em tubetes seguidas de mesma letra, não diferem pelo teste t $(\mathrm{P}>0,90)$.

\section{CONCLUSÃO}

Para as condições que foi realizado o trabalho, recomenda-se produzir mudas de Schinus terebinthifolius em tubetes de $280 \mathrm{~cm}^{3}$ e dose de $3 \mathrm{~kg}$ de Osmocote Plus ${ }^{\circledR}$ N-P-K (15-09-12) por $\mathrm{m}^{3}$ de biossólido aplicados na época da semeadura.

\section{AGRADECIMENTOS}

À Universidade Federal Rural do Rio de Janeiro (UFRRJ), ao Programa de Pós-graduação em Ciências Florestais e Ambientais (PPGCAF), à Associação PróGestão das Águas da Bacia Hidrográfica do Rio Paraíba do Sul (AGEVAP), à Coordenação de Aperfeiçoamento de Pessoal de Nível Superior (CAPES), à Companhia Estadual de Águas e Esgoto (CEDAE) e à empresa Acácia Amarela Produção de Mudas e Consultoria Ambiental Ltda.

\section{REFERÊNCIAS}

ABREU, A. H. M.; MARZOLA, L. B.; MELO, L. A.; LELES, P. S. S.; ABEL, E. L. S; ALONSO, J. M. Urban solid waste in the production of Lafoensia pacari seedlings. Revista Brasileira de Engenharia Agricola $e$ Ambiental. v. 21, n. 1, p. 83-87, 2017.
ABREU, A. H. M.; LELES, P. S. S.; MELO, L. A.; FERREIRA, D. H. A. A.; MONTEIRO, F. A. S. Produção de mudas e crescimento inicial em campo de Enterolobium contortisiliquum produzidas em diferentes recipientes. Floresta. v. 45, n. 1, p. 141-150, 2015.

ASSENHEIMER, A. Benefícios do uso de biossólidos como substratos na produção de mudas de espécies florestais. Ambiência. v. 5, n. 2, p. 321-330, 2009.

BELLOTTO, A.; VIANI, R. A. G.; NAVE, A. G.; GANDOLFI, F.; RODRIGUES, R. R. Monitoramento das áreas restauradas como ferramenta para avaliação da efetividade das ações de restauração e para redefinição metodológica. In: RODRIGUES, R. R.; BRANCALION, P. H. S; ISERNHAGEN, I. Pacto Pela Restauração da Mata Atlântica: referencial dos conceitos e ações de restauração florestal. São Paulo, SP: Instituto BioAtlântica, 2009. p. 128-148.

BERTON, R. S.; NOGUEIRA, T. A. R. Uso de lodo de esgoto na agricultura. In: COSCIONE, A. R.; NOGUEIRA, T. A. R.; PIRES, A. M. M. Uso agrícola de lodo de esgoto - Avaliação após a resolução no 375 do CONAMA. Botucatu, SP: FEPAF, 2010. p. 31-50.

BETTIOL, W.; CAMARGO, O. De. Lodo de esgoto: Impactos ambientais na agricultura. Jaguariuna, SP: Embrapa Meio Ambiente, 2006. p. 349. 
BRONDANI, G. E.; SILVA, A. J. C.; REGO, S. S.; GRISI, F. A.; NOGUEIRA, A. C.; WNDLING, I.; ARAUJO, M. A. Fertilização de liberação lenta controlada no crescimento inicial de angico-branco. Scientia Agraria. v. 9, n. 2, p. 167-176, 2008.

CALDEIRA, M. V. W.; BLUM, H.; BALBINOT, R.; LOMBARDI, K. C. Composto orgânico na produção de mudas de aroeira vermelha. Scientia Agraria. v. 9, p. 27-33, 2008.

CARNEIRO, J. G. de A. Produção e controle de qualidade de mudas florestais. Curitiba, PR: FUPEF, 1995. p. 451.

CARVALHO, P. E. R. Espécies arbóreas brasileiras. Brasília, DF: Embrapa Informação Tecnológica, 2003. v. 1.p. 1039.

COSCIONE, A. R.; NOGUEIRA, T. A. R.; PIRES, A. M. M. Uso agrícola de lodo de esgoto - Avaliação após a Resolução no 375 do CONAMA. Botucatu, SP: FEPAF, 2010. p. 408.

CUNHA, A. O.; ANDRADE, L. A.; BRUNO, R. L. A.; SILVA J. A. L.; SOUZA, V. C. Efeito dos substratos e das dimensões dos recipientes na qualidade de mudas de Tabebuia impetiginosa (Mart. Ex. D. C.) Standl. Revista Árvore. v. 29, n. 4, p. 507-516, 2005.

FERNANDES, M. S. Nutrição Mineral de Plantas. Viçosa, MG: Sociedade Brasileira de Ciência do Solo, 2006. p. 432.

FERRAZ, A. V.; ENGEL, V. L. Efeito do tamanho de tubetes na qualidade de mudas de jatobá (Hymenaea courbaril L. var. stilbocarpa (Hayne) Lee et Lang.), ipêamarelo (Tabebuia chrysotricha (Mart. ex Dc.) Sandl.) e guarucaia (Parapiptadenia rigida (Benth.) Brenan). Revista Arvore. v. 35, n. 3, p. 413-423, 2011.

GONÇALVES, J. L. M.; MENDES, K. C. F. S.; SASAKI, C. M. Mineralização de nitrogênio em ecossistemas florestais naturais e implantados do Estado de São Paulo. Revista Brasileira de Ciência do Solo. v. 25, p. 601-616, 2001.

GRAYBILL, F. A. Theory and application of the linear model. Belmont: Duxbury, 2000. p. 704.
HAHN, C. M.; OLIVEIRA, C.; AMARAL, E. M.; RODRIGUES, M. S.; SOARES, P. V. Recuperação florestal: da semente à muda. São Paulo, SP: Secretaria do Meio Ambiente para a Conservação e Produção Florestal do Estado de São Paulo, 2006. p. 144.

INEA - INSTITUTO ESTADUAL DO AMBIENTE. Resolução INEA no 89, de 03/06/2014. Diário Oficial do Estado do Rio de Janeiro, Rio de Janeiro, RJ, cinco de junho de 2014. Disponível em: http://www.inea.rj.gov.br/cs/groups/public/documen ts/document/zwew/mdu5/ edisp/inea0059810.pdf. Acesso em: 25 jan. 2017.

JOSÉ, A. C.; DAVIDE, A. C.; OLIVEIRA, S. L. Produção de mudas de aroeira (Schinus terebinthifolius Raddi) para recuperação de áreas degradas pela mineração de bauxita. Cerne. v. 11, n. 2, p. 187-196, 2005.

JOSÉ, A. C.; DAVIDE, A. C.; OLIVEIRA, S. L. Efeito do volume do tubete, tipo e dosagem de fertilizante na produção de mudas de aroeira (Schinus terebinthifolia Raddi). Revista Agrarian. v. 2, n. 3, p. 73-86, 2009.

LIMA FILHO, P. Biossólido na restauração florestal: produção de mudas e adubação de plantio. 2015. $98 \mathrm{f}$. Dissertação (Mestrado em Ciências Florestais e Ambientais) - Instituto de Florestas, Universidade Federal Rural do Rio de Janeiro, Seropédica, Rio de Janeiro, 2015.

LISBOA, A. C.; LELES, P. S. S.; OLIVEIRA NETO, S. N. O.; CASTRO, D. N.; ABREU, A. H. M. Efeito do volume de tubetes na produção de mudas de Calophyllum brasiliense e Toona ciliata. Revista árvore. v. 36, n. 4, p. 603-609, 2012.

MAAS, K. D. B. Biossólido como substrato na producão de mudas de timburi. 2010. 46 f. Dissertação (Mestrado em Ciências Florestais e Ambientais) - Universidade Federal de Mato Grosso, Cuiabá, Mato Grosso, 2010.

MENDONÇA, V.; ARRUDA, N. A. A.; SOUZA, H. A.; TEIXEIRA, G. A.; HAFLE, O. M.; RAMOS, J. D. Diferentes ambientes e Osmocote Plus ${ }^{\circledR}$ na produção de mudas de tamarindeiro (Tamarindus indica). Ciência e Agrotecnologia. v. 32, n. 2, p. 391-397, 2008. 
NOVAIS, R. F.; SMYTH, T. J.; NUNES, F. N. Fósforo. In: NOVAIS, R. F.; ALVAREZ V. V. H.; BARROS, N. F.; FONTES, R. L. F.; CANTURUTTI, R. B.; NEVES, J. C. L. Fertilidade do Solo. Viçosa, MG: Sociedade Brasileira de Ciência do Solo, 2007.

PAIVA, A. V.; POGGIANI, F.; GONÇALVES, J. L. M.; FERRAZ, A. V. Crescimento de mudas de espécies arbóreas nativas, adubadas com diferentes doses de lodo de esgoto seco e com fertilização mineral. Scientia Forestalis. v. 37, n. 84, p. 499-511, 2009.

ROSSA, U. B.; ANGELO, A. C.; NOGUEIRA, A. C.; WESTPHALEN. D. J.; BASSACO, M. V. M.; MILANI, J. E. F.; BIANCHIN, J. E. Fertilizante de liberação lenta no desenvolvimento de mudas de Schinus terebinthifolius e Sebastiania commersoniana. Revista Floresta. v. 43, n. 1, p. 93-104, 2013.

ROSSA, U. B.; ANGELO, A. C.; BOGNOLA, I. A.; WESTPHALEN. D. J.; MILANI, J. E. F. Fertilizante de liberação lenta no desenvolvimento de mudas de Eucalyptus grandis. Revista Florestal. v. 45, n. 1, p. 85-96, 2015.

SORREANO, M. C. M.; RODRIGUES, R. R.; BOARETTO, A. E. Guia de nutrição para espécies florestais nativas. São Paulo, SP: Oficina de Textos, 2012. p. 256.
STÜPP, A. M.; NAVROSKI, M. C.; FELIPPE, D.; KNIESS, D. D. C.; AMANCIO, J. C.; SILVA, M. A; PEREIRA, M. O. Crescimento de mudas de Mimosa scabrella Benth em função de diferentes tamanhos de recipientes e doses de fertilizante. Ecologia e Nutrição Florestal. v. 3, n. 2, p. 40-47, 2015.

TAIZ, L.; ZEIGER, E. Fisiologia vegetal. Porto Alegre, RG: Artmed, 2013. p. 848.

TEIXEIRA, S. A.; MAIOCHI, R. A.; GIRARDI, C. G.; SCHORN, L. A. Efeito de diferentes tamanhos de sacos plástico, na produção de mudas de Triplaris americana L. e Jacaranda micrantha Cham. Revista Brasileira de Biociências. v. 5, p. 765-767, 2005.

TRIGUEIRO, R.M., GUERRINI, I.A. Uso de biossólido como substrato para produção de mudas de eucalipto. Scientia Florestalis. n. 64, p. 150-162, 2003.

VIANA, J. S.; GONÇALVES, E. P.; ANDRADE, L. A.; OLIVEIRA, L. S. B.; SILVA, E. O. Crescimento de mudas de Baubinia forficata Link. em diferentes tamanhos de recipientes. Revista Floresta. v. 38, n. 4, p. 663-671, 2008. 